\title{
Litigation escalates for patents on a chip
}

The latest development in gene chip technology has shifted the ground from the laboratory to the courtrooms. Hyseq (Sunnyvale, CA), owner of two patents on using oligonucleotides to determine the sequence of a piece of DNA (sequencing by hybri-dization), filed a complaint on March 4 against Affymetrix (Santa Clara, CA) for infringement of the patents. HySeq is a private company set up specifically to exploit the technology and patents of Radoje
Affymetrix's gene chip: Mutation detector or gene sequencer or both?
DNA mix. If you detect all the possible sequences in an unsequenced piece of DNA, then you have re-sequenced the DNA, and the only remaining problem is the 10,000 piece jigsaw puzzle of putting the pieces together. This has actually turned out to be quite hard, so most of the active groups now are using the technology merely to resequence genes, thus detecting all the possible mutations in a gene in one experiment. Affymetrix, for instance, has developed GeneChips to detect mutations in HIV reverse transcriptase, cystic fibrosis transmembrane protein, and Drmanac and Radomir Crkvenjakov, now at Argonne National Laboratory (Argonne, IL). Affymetrix is the DNA chip spinout of combinatorial chip company Affymax, now a subsidiary of GlaxoWellcome (London). After over 3 years of private disagreement about the relevance of HySeq's patents to gene chip technology, the companies are going for the courts.

This is the latest of a series of patent cases involving seven companies in gene chip technology development over who exactly invented, and hence owns, the sequencing by hybridization concept. In the $1980 \mathrm{~s}$, several researchers realized that you could deduce DNA sequence from patterns of oligonucleotide hybridization. For example, a complete panel of all possible 8-mers can be hybridized to a 200-base DNA fragment, and the fragment's sequence, in theory, be deduced from the pattern of hybridization. In 1987, a group from what was then Yugoslavia filed a patent on this concept. Although the concept was described by no less that four other groups between 1988 and 1991-all apparently independently-the concept was considered nonobvious and in 1993 the patent was granted.

In theory, one way to do sequencing by hybridization is to make a huge panel of oligonucleotides on a surface-a "gene chip" - and hybridize a labeled target DNA to it. This is an extension of the "reverse dot blot"-using small arrays of oligonucleotides to detect specific sequences in a

William Bains assesses investment proposals for Merlin Ventures in London and has researched into sequencing by hybridization. He has worked as a consultant for Affymetrix. tumor suppressor genes.

This is one of the bases for disagreement. Affymetrix claims that what they are doing is not sequencing, but mutation detection. Not so, says HySeq: Lewis Gruber, president and CEO of HySeq, points out that, "if you detect every mutation at every position in a gene then you are resequencing the gene." So HySeq says that what Affymetrix and others are doing is sequencing by hybridization, and thus covered by their patent. Affymetrix maintains that HySeq's patent only covers a specific algorithm for using oligonucleotides to sequence DNA, and that its process is different both in principle and in practice. "HySeq is asserting its patents cover all probe-based algorithms for sequencing and sequence checking," says Affymetrix's Vern Norviel, who believes that HySeq's claim is unrealistic. Nevertheless, HySeq believes that its patent covers any use of oligonu-
Human cloning and human "enhancement" via gene therapy occupied bioethicists gathered separately at two meetings in Washington, DC in March.

Immediately after researchers at the Roslin Institute and the pharming company PPL Therapeutics (Roslin, UK) showed they had cloned a sheep from a mature animal's differentiated cell, US President Bill Clinton asked the US National Bioethics Advisory Commission (NBAC, Washington, DC) to review the associated legal and ethical issues and report back within 90 days. The NBAC cleotides to discover the sequence of DNA.

One thing that both companies agree on is their opposition to the European patent filed by Ed Southern of Oxford University (Oxford, UK), which also claims sequencing by hybridization and gene chip technology. Southern's patent was filed in 1988, and its claims include both the sequencing by hybridization concept and the gene chip. Hyseq and six other companies, among them Affymetrix, have entered an "opposition" to this patent, a legal proceeding to say that the Southern patent is invalidated by previous patent filings.

The Southern case will not come to court for a year, and the appeals process will take until 2000 to conclude in Europe. The HySeq vs. Affymetrix case is coming before the relatively speedy Northern District Court of California, and should be heard for the first time in 1998. It is likely that the legal systems of the two continents will conclude matters sometime after 2003. In the meantime, other applications of highly parallel oligonucleotide hybridization will be developed and will (or will not) be considered to be variants of sequencing by hybridization.

Is this benefiting anyone? HySeq believes that the inventors of a technology should get value from it by getting people to use it. "Our goal is to get everyone in the world using sequencing by hybridization. We are not trying to retard progress here," says Gruber. Affymetrix echoes the sentiment, but believes that Drmanac and Crkvenjakov are not the inventors of what Affymetrix is doing, and that the best way to get scientists to use sequencing by hybridization is to continue to develop the technology to make it work.

William Bains

\section{Bioethicists ruminate separately on clones, gene 'enhancements'}

quickly invited scientific experts, clergy, ethicists, philosophers, lawyers, and other interested individuals to consider both technical and ethical issues related to mammalian cloning.

The views of the assembled experts ranged widely-expressing everything from enthusiasm over the medical prospects of such work, to skepticism about whether mammalian cloning is truly practicable, to repugnance. Some individuals expressing these views refer to their own instinctive responses, whereas others cite either religious 